\title{
PET Imaging of Estrogen Receptors as a Diagnostic Tool for Breast Cancer Patients Presenting with a Clinical Dilemma
}

\author{
Michel van Kruchten ${ }^{1}$, Andor W.J.M. Glaudemans ${ }^{2}$, Erik F.J. de Vries ${ }^{2}$, Regina G.H. Beets-Tan ${ }^{3}$, Carolien P. Schröder ${ }^{1}$, \\ Rudi A. Dierckx ${ }^{2}$, Elisabeth G.E. de Vries $^{1}$, and Geke A.P. Hospers ${ }^{1}$ \\ ${ }^{1}$ Department of Medical Oncology, University Medical Center Groningen, University of Groningen, Groningen, The Netherlands; \\ ${ }^{2}$ Department of Nuclear Medicine and Molecular Imaging, University Medical Center Groningen, University of Groningen, \\ Groningen, The Netherlands; and ${ }^{3}$ Department of Radiology, Maastricht University Medical Center, Maastricht, The Netherlands
}

$16 \alpha-{ }^{18} \mathrm{~F}$-fluoro-17 $\beta$-estradiol $\left({ }^{18} \mathrm{~F}-\mathrm{FES}\right)$ is an estrogen receptor (ER)-specific PET tracer with various potential interesting applications. The precise contribution of this technique in current clinical practice, however, has yet to be determined. Therefore, the aim of this study was to evaluate the value of ${ }^{18} \mathrm{~F}-\mathrm{FES}$ PET in breast cancer patients presenting with a clinical dilemma. Methods: ${ }^{18}$ F-FES PET examination could be requested by referring physicians for patients with a history of ER-positive breast cancer and the presence of a clinical dilemma despite complete standard work-up. All requests for ${ }^{18} \mathrm{~F}-\mathrm{FES}$ PET required a positive arbitration by a dedicated medical oncologist and nuclear medicine physician. The referring physician was asked to fill in validated questionnaires before, shortly after, and at more than 3 mo after ${ }^{18} \mathrm{~F}$-FES PET to determine indication, diagnostic value, and therapeutic consequences of ${ }^{18} \mathrm{~F}-$ FES PET. To further validate ${ }^{18} \mathrm{~F}$-FES PET findings, ${ }^{18} \mathrm{~F}$-FES PET lesions were quantified and compared with centrally reviewed conventional imaging. Results: Thirty-three patients underwent ${ }^{18}$ F-FES PET between December 2008 and October 2010. ${ }^{18} \mathrm{~F}-\mathrm{FES}$ PET was requested to evaluate equivocal lesions on conventional work-up ( $n=21$ ), ER status in metastatic patients $(n=10)$, and the origin of metastases $(n=2) .{ }^{18} \mathrm{~F}-$ FES-positive lesions were observed in 22 patients. ${ }^{18} \mathrm{~F}-\mathrm{FES}$ PET was especially sensitive for bone metastases, detecting 341 bone lesions, compared with 246 by conventional imaging. The sensitivity for liver metastases was poor, and quantification of ${ }^{18} \mathrm{~F}-\mathrm{FES}$ uptake in liver lesions was hampered by high physiologic background. ${ }^{18} \mathrm{~F}-\mathrm{FES}$ uptake was highly variable between all metastases (range of standardized uptake value, $1.20-18.81$ ), and $45 \%$ of the patients with a positive ${ }^{18} \mathrm{~F}-\mathrm{FES}$ PET finding had both ${ }^{18} \mathrm{~F}-\mathrm{FES}$-positive and ${ }^{18} \mathrm{~F}-\mathrm{FES}$-negative metastases. ${ }^{18} \mathrm{~F}$-FES PET improved diagnostic understanding in $88 \%$ of the patients and led to therapy change in $48 \%$ of the patients. Conclusion: With the exception of liver metastases, whole-body imaging of ER expression with ${ }^{18} \mathrm{~F}$-FES PET can be a valuable additional diagnostic tool when standard work-up is inconclusive. ${ }^{18} \mathrm{~F}$-FES PET supported therapy decisions by improving diagnostic understanding and providing information on ER status of tumor lesions.

\footnotetext{
Received May 23, 2011; revision accepted Oct. 7, 2011.

For correspondence or reprints contact: Geke A.P. Hospers, Department of Medical Oncology, University Medical Center Groningen, P.O. Box 30.001, 9700 RB Groningen, The Netherlands.

E-mail: g.a.p.hospers@int.umcg.nl

Published online Jan. 12, 2012.

COPYRIGHT (C 2012 by the Society of Nuclear Medicine, Inc
}

Key Words: estrogen receptor; imaging; breast cancer; ${ }^{18} \mathrm{~F}-$ FES PET; clinical value

J Nucl Med 2012; 53:182-190

DOI: 10.2967/jnumed.111.092734

B reast cancer is the most common cancer in women in the Western world (1). Approximately $75 \%$ of the tumors express the estrogen receptor (ER) at diagnosis (2). Knowledge of the ER status of a patient has important consequences for treatment decision making, because patients with ER-positive tumors are likely to respond to antihormonal therapy (3).

Evaluation of ER status is therefore performed by means of immunohistochemical staining of the primary tumor. This golden standard has some limitations: it predicts tumor response to antihormonal therapy correctly in only $50 \%-$ $60 \%$ of the patients $(4,5)$. The technique is semiquantitative, which can result in interobserver variation, and ER scoring depends on the antibody used and delay-to-fixation time $(6,7)$. The recent systematic review by the American Society of Clinical Oncology and the College of American Pathologists revealed that up to $20 \%$ of all immunohistochemical determinations worldwide are inaccurate (8). Absence of ER expression does, however, have a strong negative predictive value for response to antihormonal therapy (9).

Also during metastatic disease, evaluation of ER status is important to determine changes in receptor expression. This evaluation is of relevance because discordant ER expression between primary tumor and metastatic lesions occurs in $18 \%-55 \%$ of the patients $(10,11)$. A recent study in 336 patients with an ER-positive primary tumor revealed loss of ER expression in distant metastases in $36 \%$ of these patients, which was a predictor of poor response to antihormonal therapy (12). For this reason, guidelines of the European Society for Medical Oncology and National Comprehensive Cancer Network recommend repeated biopsies $(13,14)$. In addition, biopsies of suspected recurrences are advised to confirm the diagnosis of metastasized breast 
cancer and to exclude benign lesions or (metastases from) a second cancer.

Despite these clear indications for rebiopsy, this may not always be feasible because of the characteristics of the lesion (such as location) or the patient (such as comorbidity). Additionally, within a single tumor or across lesions within a patient, ER expression can be heterogeneous (15). In these cases, a single biopsy may not be representative of the ER characteristics of the tumor burden as a whole. Furthermore, physicians may be reluctant to perform biopsies given the invasive nature of the procedure. A noninvasive method to quantify ER expression in all metastatic lesions would therefore be valuable.

Whole-body PET with $16 \alpha-{ }^{18} \mathrm{~F}$-fluoro- $17 \beta$-estradiol $\left({ }^{18} \mathrm{~F}-\mathrm{FES}\right)$ provides a unique method to noninvasively obtain molecular information about ER expression $(16,17)$. Several studies have shown that ${ }^{18} \mathrm{~F}$-FES PET can reliably detect ER-positive tumor lesions and that ${ }^{18} \mathrm{~F}$-FES uptake correlates well with immunohistochemical scoring for ER (18-20). Furthermore, low ${ }^{18} \mathrm{~F}-\mathrm{FES}$ uptake was a strong predictor for failure of antihormonal therapy (21-23). On the basis of these results, ${ }^{18}$ F-FES PET examinations have been routinely requested in our center since December 2008 for patients with a history of ER-positive breast cancer in whom a clinical dilemma remained despite complete standard work-up (e.g., when imaging procedures were inconclusive and performing a biopsy was not feasible). The aim of this study was to determine the value of ${ }^{18} \mathrm{~F}$-FES PET in breast cancer patients presenting with a clinical dilemma.

\section{MATERIALS AND METHODS}

\section{Patients}

Patients with a history of histologically proven ER-positive breast cancer were eligible for routine ${ }^{18} \mathrm{~F}$-FES PET examination when, despite complete standard work-up, they presented a clinical dilemma for their treating physician. All requests for ${ }^{18} \mathrm{~F}$-FES PET required a positive arbitration by a dedicated medical oncologist and nuclear medicine physician. A detailed medical history, current complaints, laboratory results (if available), and conventional imaging results were collected from all patients. The informed consent requirements for these retrospectively enrolled patients were waived by the University Medical Center Groningen Institutional Review Board (METc 2010.102).

\section{Standard Work-up}

The routine staging protocol for these patients adheres to the Dutch Breast Cancer Guidelines, which are highly comparable with National Comprehensive Cancer Network guidelines (version 2.2011) (13). In short, work-up for disseminated disease includes chest CT or chest imaging, CT of the abdomen or ultrasound of the liver, and bone scanning. During follow-up, examinations are directed by signs and symptoms and include bone scanning or MRI in the case of localized bone pain or elevated alkaline phosphate; chest CT in the case of chest lesions or pulmonary complaints; and abdomen $\mathrm{CT}$ in the case of abdominal lesions or abnormal liver tests. The use of ${ }^{18} \mathrm{~F}$-FDG PET is discouraged and limited to patients with equivocal lesions, although tissue biopsy is more likely to provide useful information in these cases. Biopsies of suspected distant recurrences are recommended to confirm the diagnosis of metastatic breast cancer and evaluate receptor status.

\section{${ }^{18}$ F-FES PET}

ER antagonists were discontinued for a minimum of $5 \mathrm{wk}$ before ${ }^{18}$ F-FES PET to prevent false-negative results. The use of aromatase inhibitors was allowed. ${ }^{18} \mathrm{~F}$-FES was produced as previously described (24). ${ }^{18} \mathrm{~F}$-FES that was ready for injection was obtained in a $32 \% \pm 10 \%$ decay-corrected radiochemical yield. Specific activity was $182 \pm 101 \mathrm{MBq} / \mathrm{nmol}$, with a radiochemical purity of $99.9 \% \pm 0.3 \%$. Patients received ${ }^{18} \mathrm{~F}$-FES $(207 \pm 8$ $\mathrm{MBq}$ ) intravenously. Whole-body ${ }^{18} \mathrm{~F}$-FES PET was performed 60 min after tracer injection, using an ECAT Exact HR + PET camera (Siemens CTI) (spatial resolution, $5 \mathrm{~mm}$; emission time, $5 \mathrm{~min}$; and transmission time, $2 \mathrm{~min}$ per bed position) or a 64-slice $\mathrm{mCT}$ (PET/CT) camera (Siemens CTI), with 2-mm spatial resolution with an emission time of $3 \mathrm{~min}$ per bed position and a transmission CT scan for attenuation correction. All scans and quantifications were obtained according to the guidelines for tumor PET of the European Association of Nuclear Medicine (25). Scans were reconstructed with a gaussian filter of $5 \mathrm{~mm}$ in full width at half maximum, and iterative reconstruction methods were used with 3 iterations and 24 subsets. PET images were assessed qualitatively and quantitatively by a nuclear medicine physician. In reference to other ${ }^{18} \mathrm{~F}$-FES PET studies, we used the maximum SUV (SUVmax) to quantify ER expression and a cutoff value of 1.5 or more to dichotomize results into ER-positive and ER-negative (20). When in the field of view, CT data were used to allocate PET-positive lesions to an anatomic substrate.

\section{Analysis of Imaging Results}

Imaging analysis was performed retrospectively. Lesions detected by ${ }^{18} \mathrm{~F}$-FES PET were recorded, and ${ }^{18} \mathrm{~F}$-FES uptake was quantified. When a patient had innumerable lesions, an arbitrary maximum of 40 lesions was recorded. Aside from evaluation of the routine radiology and nuclear medicine reports, conventional imaging was centrally reevaluated, with the investigators masked to other imaging results. All lesions were classified into benign, equivocal, and metastatic categories. Thereafter, conventional imaging results were compared with findings on ${ }^{18} \mathrm{~F}-\mathrm{FES}$ PET. For discordant lesions, a fusion of ${ }^{18} \mathrm{~F}-\mathrm{FES}$ PET with CT, MRI, or ${ }^{18}$ F-FDG PET and a one-to-one comparison between ${ }^{18}$ F-FES PET and bone scanning were performed for final classification of these lesions. Follow-up imaging and clinical data were reviewed, whenever available, to evaluate remaining discordances.

\section{Clinical Value}

Validated questionnaires were used to collect the insight of the referring physician before, shortly after, and more than 3 mo after ${ }^{18}$ F-FES PET (26). Questionnaire 1 served to identify the clinical dilemma and intended therapeutic strategy. Using the reason for ${ }^{18}$ F-FES PET examination, we retrospectively categorized the patients into 3 different groups. Questionnaire 2 permitted us to evaluate the outcome of ${ }^{18} \mathrm{~F}$-FES PET study and the influence of the exam on treatment decision making. The last questionnaire served to analyze the value of ${ }^{18}$ F-FES PET on diagnostic understanding and therapy management after a follow-up of at least 3 mo, using a 5-point scale (Table 1). The scoring was performed by the referring physicians. All questionnaires were checked for internal consistency. 


\begin{tabular}{|c|c|}
\hline Score & Answer \\
\hline \multicolumn{2}{|c|}{ Diagnostic understanding } \\
\hline 1 & $\begin{array}{l}{ }^{18} \mathrm{~F}-\mathrm{FES} \text { PET confused my understanding of this patient's disease and led to investigations } \\
\text { I would not otherwise have done. }\end{array}$ \\
\hline 2 & $\begin{array}{l}{ }^{18} \mathrm{~F}-\mathrm{FES} \text { PET confused my understanding of this patient's disease but did not lead to } \\
\text { any additional investigations. }\end{array}$ \\
\hline 3 & ${ }^{18} \mathrm{~F}-\mathrm{FES}$ PET had little or no effect on my understanding of this patient's disease. \\
\hline 4 & $\begin{array}{l}{ }^{18} \mathrm{~F}-\mathrm{FES} \text { PET provided information that substantially improved my understanding of this } \\
\text { patient's disease. }\end{array}$ \\
\hline 5 & $\begin{array}{l}\text { My understanding of this patient's disease depended on diagnostic information provided only by } \\
18 \text { F-FES PET (unavailable from any other nonsurgical procedure). }\end{array}$ \\
\hline \multicolumn{2}{|c|}{ Therapeutic choice } \\
\hline 1 & ${ }^{18} \mathrm{~F}-\mathrm{FES}$ PET led me to choose treatment that in retrospect was not in the best interests of the patient. \\
\hline 2 & ${ }^{18} \mathrm{~F}$-FES PET was of no influence in my choice of treatment. \\
\hline 3 & ${ }^{18} \mathrm{~F}-\mathrm{FES}$ PET did not alter my choice of treatment but did increase my confidence in the choice. \\
\hline 4 & $\begin{array}{l}{ }^{18} \mathrm{~F}-\mathrm{FES} \text { PET contributed to a change in my chosen treatment but other factors (other imaging tests, } \\
\text { other diagnostic tests, changes in patient status) were equally or more important. }\end{array}$ \\
\hline 5 & $\begin{array}{l}{ }^{18} \mathrm{~F}-\mathrm{FES} \mathrm{PET} \text { was very important compared with other factors in leading to a beneficial change } \\
\text { in treatment. }\end{array}$ \\
\hline
\end{tabular}

\section{Statistical Analysis}

Differences in tracer uptake between different (patients and) organs were analyzed by a 1-way ANOVA. Site-to-site variability in ${ }^{18} \mathrm{~F}$-FES uptake was expressed as coefficient of variability. Scores on diagnostic understanding and therapeutic consequences were calculated for the 3 different reasons for ${ }^{18}$ F-FES PET examination with a 2-sided nonparametric Kruskal-Wallis test.

\section{RESULTS}

\section{Patient Characteristics}

Thirty-three patients were referred for ${ }^{18}$ F-FES PET examination between December 2008 and October 2010. Patients were retrospectively divided into 3 groups that were based on the reason for the ${ }^{18} \mathrm{~F}$-FES PET examination: to differentiate between benign and malignant lesions in the case of equivocal or ambiguous work-up $(n=21)$, to evaluate the patients' ER status $(n=10)$, and to differentiate between metastases originating from different tumor types $(n=2)$. Patient characteristics are shown in Table 2.

\section{${ }^{18}$ F-FES PET and Conventional Imaging Results}

${ }^{18} \mathrm{~F}$-FES PET was performed in 22 patients and ${ }^{18} \mathrm{~F}$-FES PET/CT in 11. Work-up before ${ }^{18} \mathrm{~F}$-FES PET consisted of CT $(n=24)$, bone scanning ( $n=23$ patients), MRI $(n=$ 8 ), and ${ }^{18} \mathrm{~F}$-FDG PET $(n=3)$. Ultrasound and radiographic images were not considered in our analysis. Biopsy of suggestive lesions was performed before ${ }^{18} \mathrm{~F}$-FES PET in 4 patients and during follow-up in 2 . PET showed ${ }^{18} \mathrm{~F}-\mathrm{FES}-$ positive metastases in 22 of the 33 patients. No apparent false-positives were noted in a patient-based analysis.

${ }^{18}$ F-FES PET was negative in 11 patients. In 3 patients, ${ }^{18}$ F-FES PET showed no tumor lesions despite the presence of metastases, matching the histologic findings (ERnegative) in tumor biopsy in 2 patients. In 1 patient, 3 mo later, biopsy showed an immunohistochemical ER-positive metastasis in the liver. In the remaining 8 patients, the negative ${ }^{18}$ F-FES PET findings concurred with the absence of metastases during follow-up of 6 mo.

In total, 398 lesions were detected by ${ }^{18} \mathrm{~F}$-FES PET. Lesions were located in bone ( $n=341$ lesions), lymph nodes $(n=26)$, lung or pleura $(n=19)$, liver $(n=8)$, and soft tissue $(n=4)$. Although investigators were unaware of the ${ }^{18} \mathrm{~F}$-FES PET results, they detected 242 of these $398{ }^{18} \mathrm{~F}$-FES-positive lesions $(61 \%)$ on conventional imaging. After comparison between conventional imaging and ${ }^{18}$ F-FES PET, an additional 79 lesions with ${ }^{18}$ F-FES uptake could also be detected using conventional techniques. Of the remaining lesions, 15 were confirmed during follow-up. Therefore, most ${ }^{18}$ F-FES PET lesions $(n=336$, $84 \%$ ) could eventually be validated by conventional techniques. The remaining 62 lesions were not detected during follow-up. However, nearly all these lesions were additional bone metastases in patients with known bone metastases. It is therefore plausible that these lesions are also true-positives.

Investigators (who were unaware of the ${ }^{18} \mathrm{~F}-\mathrm{FES}$ PET results) detected a total of 319 metastases on conventional imaging. Of these, ${ }^{18} \mathrm{~F}$-FES PET missed 77 lesions (24\%). The detection of liver metastases by ${ }^{18} \mathrm{~F}$-FES PET was poor. None of 7 patients with known liver metastases had increased focal ${ }^{18} \mathrm{~F}$-FES uptake. In 2 patients, however, cold spots were observed at the site of liver metastases, and in 2 others ${ }^{18}$ F-FES uptake was more heterogeneous than in other patients. Also, relatively few lymph nodes were detected by ${ }^{18}$ F-FES PET (26/55 lymph nodes, $47 \%$ ). However, $68 \%$ of the undetected nodes had diameters less 15 $\mathrm{mm}$ (Response Evaluation Criteria in Solid Tumors, version 
TABLE 2

Patient Characteristics

\begin{tabular}{|c|c|c|c|c|}
\hline Characteristic & Category I $(n=21)$ & Category II $(n=10)$ & Category III $(n=2)$ & All patients $(n=33)$ \\
\hline \multicolumn{5}{|l|}{ Age $(y)$} \\
\hline Mean & 57 & 61 & 55 & 58 \\
\hline Range & $43-78$ & $48-77$ & $54-56$ & $43-78$ \\
\hline \multicolumn{5}{|l|}{$\operatorname{Sex}(n)$} \\
\hline Male & 0 & 0 & 0 & 0 \\
\hline Female & 21 & 10 & 2 & 33 \\
\hline \multicolumn{5}{|l|}{ Menopausal status (n) } \\
\hline Premenopausal & 1 & 0 & 0 & 1 \\
\hline Postmenopausal & 16 & 10 & 2 & 28 \\
\hline Unknown & 4 & 0 & 0 & 4 \\
\hline \multicolumn{5}{|l|}{ Breast cancer stage $(n)$} \\
\hline Suspected distant recurrence & 12 & 0 & 2 & 14 \\
\hline Metastatic & 9 & 10 & 0 & 19 \\
\hline \multicolumn{5}{|l|}{ Prior lines of endocrine therapy $(n)^{\star}$} \\
\hline 0 & 13 & 0 & 2 & 15 \\
\hline 1 & 5 & 4 & 0 & 9 \\
\hline$>1$ & 3 & 6 & 0 & 9 \\
\hline \multicolumn{5}{|l|}{$\begin{array}{c}\text { Time between primary diagnosis } \\
\text { and }{ }^{18} \text { F-FES PET }(y)\end{array}$} \\
\hline Mean & 8 & 10 & 3 & 8 \\
\hline Range & $0-18$ & $3-22$ & $2-4$ & $0-22$ \\
\hline
\end{tabular}

*Does not include adjuvant antihormonal therapy.

${ }^{18} \mathrm{~F}$-FES PET examination was requested to evaluate equivocal or conflicting conventional imaging (category I), a patient's ER status (category II), or origin of metastases (category III).

1.1, cutoff value for measurable lymph node metastases), indicating that some of these may have been misclassified or were below the detection threshold for PET (27). An overview of the concordance between conventional imaging and ${ }^{18} \mathrm{~F}$-FES PET is shown in Table 3.

\section{Heterogeneity of ${ }^{18}$ F-FES Uptake}

A striking 11-fold difference in tracer uptake was observed between different patients (range of SUVmax, 1.68-18.81), and a 6-fold difference was observed between lesions within the same individual (range of SUVmax, 2.59-15.84). The coefficient of variability for the SUVmax of all ${ }^{18}$ F-FES PET lesions was high $(68 \% \pm 4 \%$, 95\% confidence interval). In $45 \%$ of the patients, both ${ }^{18} \mathrm{~F}-$ FES-positive and ${ }^{18} \mathrm{~F}-\mathrm{FES}$-negative metastases were present, suggesting partial discordant ER expression. Only 1 patient had conversion to a complete ER-negative phenotype, indicated by the absence of ${ }^{18} \mathrm{~F}$-FES uptake in all $(n=$ 4) tumor lesions. Quantification of ${ }^{18}$ F-FES uptake in liver metastases was hampered because of high physiologic

TABLE 3

Malignant Lesions Detected at Conventional Imaging and ${ }^{18}$ F-FES PET

\begin{tabular}{|c|c|c|c|c|c|}
\hline \multirow[b]{2}{*}{ Location } & \multirow[b]{2}{*}{$\begin{array}{l}\text { Total on conventional } \\
\text { imaging* }\end{array}$} & \multirow[b]{2}{*}{$\begin{array}{l}{ }^{18} \text { F-FES PET concordant } \\
\text { with conventional imaging }\end{array}$} & \multirow[b]{2}{*}{$\begin{array}{l}\text { Total on } \\
{ }^{18} \text { F-FES PET }\end{array}$} & \multicolumn{2}{|c|}{$\begin{array}{l}\text { Conventional imaging concordant } \\
\text { with }{ }^{18} \text { F-FES PET }\end{array}$} \\
\hline & & & & $\begin{array}{l}\text { With masking of } \\
{ }^{18} \text { F-FES result }{ }^{\star}\end{array}$ & $\begin{array}{l}\text { With knowledge } \\
\text { of }{ }^{18} \mathrm{~F}-\mathrm{FES} \text { result }{ }^{\dagger}\end{array}$ \\
\hline Bone & 246 & $212(86)$ & 341 & $212(62)$ & $292(86)$ \\
\hline Lung & 9 & $7(78)$ & 19 & $7(37)$ & $13(68)$ \\
\hline Liver & 20 & $8(40)$ & 8 & $8(100)$ & $8(100)$ \\
\hline Lymph nodes $<15 \mathrm{~mm}$ & 27 & $7(26)$ & 7 & $7(100)$ & 7 (100) \\
\hline Lymph nodes > 15 mm & 16 & $7(44)$ & 19 & $7(37)$ & $12(63)$ \\
\hline Soft tissue & 1 & $1(100)$ & 4 & $1(25)$ & $3(75)$ \\
\hline Total & 319 & $242(76)$ & 398 & $242(61)$ & $336(84)$ \\
\hline
\end{tabular}

*Lesions considered malignant after central revision while reviewers were masked to ${ }^{18}$ F-FES PET result.

${ }^{\dagger}$ Lesions considered malignant after comparison with ${ }^{18} \mathrm{~F}$-FES PET was allowed and including 15 lesions detected at follow-up shortly after ${ }^{18}$ F-FES PET ( $\left.<1 \mathrm{mo}\right)$.

Data in parentheses are percentages. 

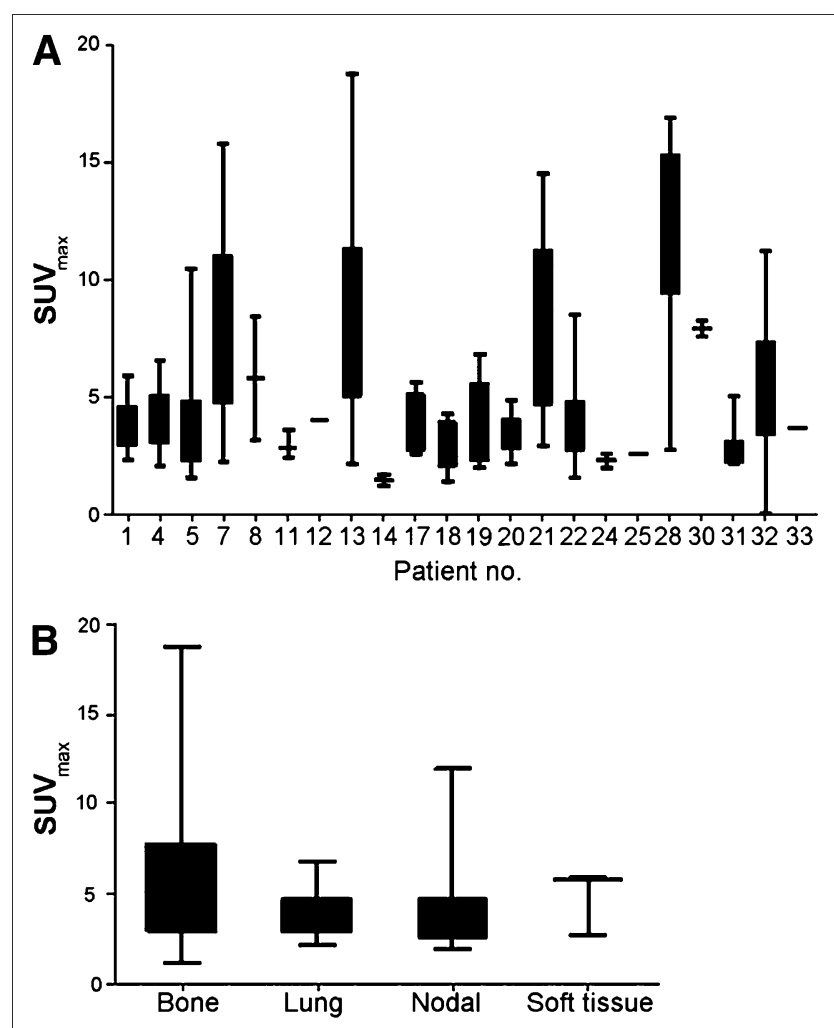

FIGURE 1. Differences in tracer uptake in all 22 patients with positive lesions on ${ }^{18} \mathrm{~F}-\mathrm{FES}$ PET $(\mathrm{A})$ and tracer uptake at different sites of metastases ( $n=398$ lesions) (B). No significant differences in average $\mathrm{SUV}_{\text {max }}$ were observed; however, bone metastases did show significantly higher coefficient of variance. Bars represent 25-75 percentiles, and whiskers represent minimal to maximum values.

uptake in surrounding normal liver tissue. Mean ${ }^{18} \mathrm{~F}-\mathrm{FES}$ uptake did not differ significantly among metastases in different organs (Fig. 1). Only 1 premenopausal patient underwent ${ }^{18}$ F-FES PET in this study. She had tracer uptake (SUV range, 1.2-1.65) in tumor lesions far below the 95\% confidence interval $(5.91 \pm 0.38)$ of the postmenopausal patients. Although it may be theoretically plausible that ${ }^{18}$ F-FES uptake depends on estrogen background level, this cannot be concluded from these limited data.

\section{Clinical Value of ${ }^{18} \mathrm{~F}$-FES PET}

${ }^{18}$ F-FES PET in Case of Equivocal or Conflicting Standard Work-up. Twenty-one patients underwent ${ }^{18} \mathrm{~F}-\mathrm{FES}$ PET to evaluate equivocal or ambiguous findings on standard work-up or for signs and symptoms for which no substrate could be found on conventional imaging. Equivocal lesions were present in bone $(n=13)$, lung $(n=4)$, liver $(n=3)$, and abdomen $(n=1)$. These patients underwent bone scanning $(n=16)$, CT $(n=16)$, MRI $(n=4),{ }^{18} \mathrm{~F}-$ FDG PET $(n=3)$, or biopsy $(n=3)$ before ${ }^{18} \mathrm{~F}$-FES PET, which did not establish a final diagnosis. In 9 of these, ${ }^{18} \mathrm{~F}-$ FES PET showed elevated uptake at the suspected lesion, confirming the presence of ER-positive metastases. Interestingly, in 3 patients biopsies before ${ }^{18} \mathrm{~F}$-FES PET did not show malignancy, despite suspected distant recurrences on conventional imaging. ${ }^{18} \mathrm{~F}-\mathrm{FES}$ PET showed multiple ${ }^{18} \mathrm{~F}-$ FES-positive lesions in these 3 patients (Fig. 2). The next therapeutic choice was affected by ${ }^{18}$ F-FES PET in 7 of 9 patients with positive ${ }^{18} \mathrm{~F}$-FES PET findings. Four of them received radiotherapy, and 1 received bisphosphonates, in addition to the intended antihormonal therapy, after ${ }^{18} \mathrm{~F}$ FES PET provided confirmation of bone metastases. In 2 patients, first-line antihormonal therapy for metastatic disease was initiated. In the remaining 12 patients, ${ }^{18} \mathrm{~F}$-FES uptake was absent in the equivocal lesion. Six months of follow-up of the lesions indicated no metastasis in 10 of 12 patients. In 2 patients, given persisting uncertainty about the nature of the lesion, a biopsy was performed. Histology showed ER-negative adenocarcinoma in 1 patient and an ER-positive liver metastasis in the other patient. In 2 patients, ${ }^{18} \mathrm{~F}$-FES PET was negative at the suspected site but revealed unknown metastases at other sites. ${ }^{18} \mathrm{~F}$-FES PET affected therapy management in only 2 patients with ${ }^{18} \mathrm{~F}-\mathrm{FES}$-negative findings. In these $2,{ }^{18} \mathrm{~F}$-FES PET led the physician to refrain from radiotherapy in the absence of ${ }^{18} \mathrm{~F}-\mathrm{FES}$ uptake at the suspected lesions and confirmed benign disease during follow-up.

${ }^{18}$ F-FES PET to Evaluate ER Expression After Progression on Antihormonal Therapy. Ten patients underwent ${ }^{18} \mathrm{~F}$ FES PET to evaluate their ER status after progression on antihormonal therapy. In these patients, there was no consensus on whether to give chemotherapy or antihormonal therapy. ${ }^{18} \mathrm{~F}$-FES PET showed increased ${ }^{18} \mathrm{~F}$-FES uptake in one or more metastatic lesions in all 10 patients. In 6 of these, there was partial discordance, with an absence of ${ }^{18} \mathrm{~F}-$ FES uptake in some metastases. In 4 patients, intended chemotherapy was switched to antihormonal therapy based on high ${ }^{18} \mathrm{~F}$-FES uptake. One patient with signs of bone marrow invasion on ${ }^{18} \mathrm{~F}$-FES PET and accompanying thrombocytopenia was switched to chemotherapy (Fig. 3).

${ }^{18}$ F-FES PET to Differentiate Between Metastases Originating from Different Tumor Types. In 2 patients, definite malignant lesions were detected by conventional imaging. It was uncertain whether these originated from the earlier ER-positive breast tumor or from another tumor type. One patient presented with a radicular syndrome in the region of root C6, 5 y after a primary breast cancer diagnosis. Neurologic examination and MRI indicated pathologic compression at vertebra $\mathrm{C} 6$, suspected to be due to a metastasis or plasmacytoma. A biopsy to prove the origin of the metastasis was considered too risky. ${ }^{18}$ F-FES PET showed uptake in C6 and T4 (Fig. 4). No other tumor lesions were observed. Therefore, this patient received antihormonal therapy for metastatic disease and radiotherapy. A second patient, known to have an ER-negative second tumor, presented with a single metastasis in the humerus. Too little material was obtained by biopsy to differentiate between the ER-positive and ER-negative primary. ${ }^{18} \mathrm{~F}-\mathrm{FES}$ PET showed no lesional uptake, suggesting an origin from the ER-negative tumor. Therefore, this patient did not receive antihormonal therapy. 


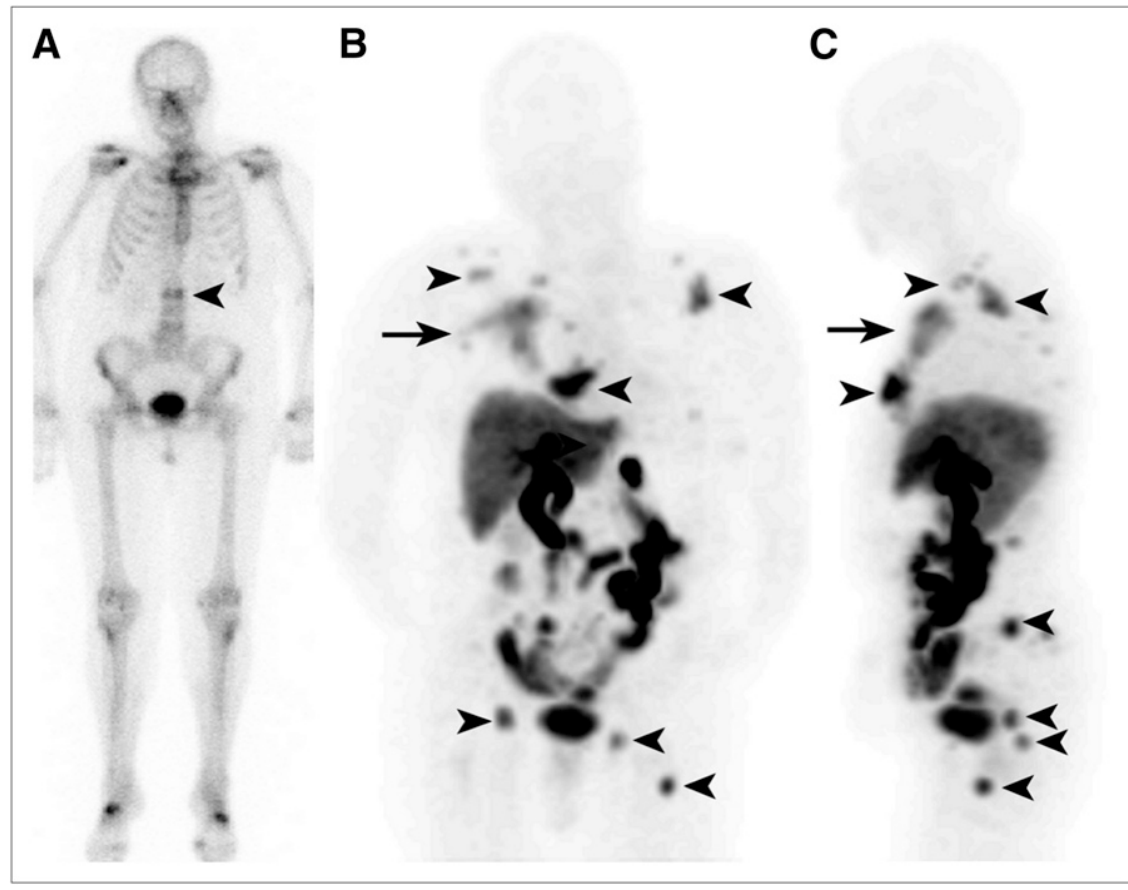

FIGURE 2. Bone scan (A) of patient showing suggestive lesion at L2 (arrowhead). Biopsy of this lesion did not show malignancy. Coronal (B) and sagittal (C) images of ${ }^{18} \mathrm{~F}$ FES PET showing ${ }^{18}$ F-FES uptake in vertebra L2 and multiple other bone metastases (arrowheads), as well as large locoregional recurrence in soft tissue (arrow). Only most intense lesions are indicated.
Questionnaires. All 3 questionnaires for the 33 patients were fully completed. Referring physicians reported an improved diagnostic understanding in 29 of the 33 patients $(88 \%)$. In 18 of these patients, improved understanding was the consequence of ${ }^{18} \mathrm{~F}$-FES PET solely, whereas in 11 patients other factors were equally or more important. Diagnostic understanding was independent of the indication for ${ }^{18} \mathrm{~F}$-FES PET $(P=0.12)$, but positive ${ }^{18} \mathrm{~F}$-FES PET results were superior $(P=0.002)$.

A change in therapeutic strategy based on ${ }^{18} \mathrm{~F}$-FES PET was reported in $16(48 \%)$ of the 33 patients. In 11 of them, information provided by ${ }^{18} \mathrm{~F}$-FES PET was important in leading to a change in therapy, whereas in 5 patients other factors were equally or more important. Showing ${ }^{18}$ F-FES uptake in equivocal lesions led to the initiation of radiotherapy $(n=4)$, bisphosphonates $(n=1)$, and antihormonal therapy $(n=3)$. The presence of ${ }^{18}$ F-FES uptake in known metastases led to the initiation of a new line of antihormonal therapy $(n=4)$. The absence of ${ }^{18}$ F-FES uptake in known metastases and in equivocal lesions, respectively, led to the discontinuation of antihormonal therapy $(n=2)$ and radiotherapy $(n=2)$ (Table 4$)$.

\section{DISCUSSION}

This is the first study, to our knowledge, evaluating the value of ${ }^{18} \mathrm{~F}$-FES PET in breast cancer patients presenting with a clinical dilemma unresolved after conventional work-up. The study shows that whole-body imaging of ER expression with ${ }^{18}$ F-FES PET can be a valuable additional diagnostic tool when conventional work-up is ambiguous and biopsies are not feasible or inconclusive.

On the questionnaires, the referring physicians reported an improved diagnostic understanding in 88\% (29/33) and therapy changes in $48 \%$ (16/33) of patients. We retrospectively divided patients who underwent ${ }^{18}$ F-FES PET into 3 groups. The first group underwent ${ }^{18} \mathrm{~F}$-FES PET to establish a diagnosis in the case of equivocal or conflicting conventional work-up. Recent guidelines (European Society for Medical Oncology/National Comprehensive Cancer Network) suggest that ${ }^{18} \mathrm{~F}$-FDG PET can be considered in the case of equivocal imaging, although biopsy is more likely to provide useful information $(13,14)$. In our patients, ${ }^{18}$ F-FDG PET was rarely requested, for various reasons (e.g., positive ${ }^{18} \mathrm{~F}-\mathrm{FDG}$ PET findings would not exclude inflammatory disease or would not differentiate between metastases from ER-positive breast cancer and metastases from another cancer origin) $(28,29) .{ }^{18} \mathrm{~F}$-FES PET has been shown to detect ER-positive metastases with high specificity (18-20). Therefore, this technique may be used as a surrogate for tissue biopsy when lesions are difficult to access. In our study, biopsies were not feasible or were inconclusive in several patients. We showed that ${ }^{18} \mathrm{~F}-\mathrm{FES}$ PET could be used to prove the presence of ER-positive metastases in the case of an equivocal conventional workup. However, ${ }^{18}$ F-FES PET cannot be used to exclude metastases in general because ER-negative metastases may be present.

In light of a possible conversion in ER phenotype, knowledge of ER expression can potentially facilitate the choice between chemotherapy and antihormonal therapy. Single-biopsy studies have shown conversion from an ERpositive to ER-negative phenotype in up to $30 \%$ of the patients. In addition, ${ }^{18} \mathrm{~F}$-FES PET studies have shown ${ }^{18} \mathrm{~F}-$ FES-negative disease in 32\%-53\% of the patients, which was highly predictive of failure to respond to antihormonal therapy. We evaluated ER expression in 10 patients in 
A

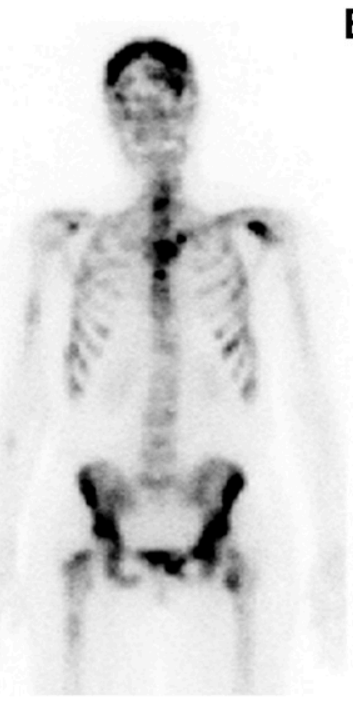

C

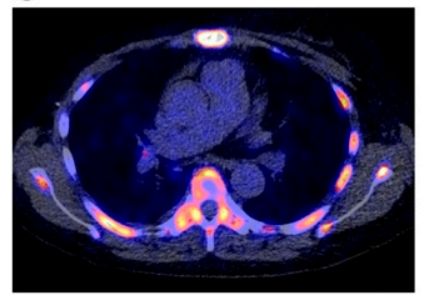

B

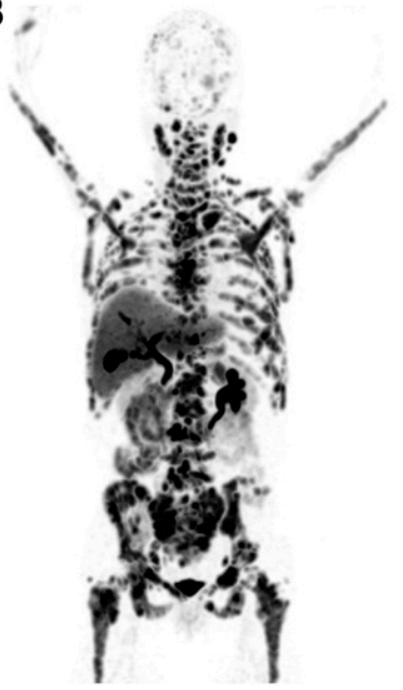

D

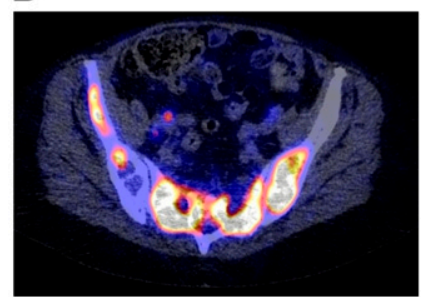

FIGURE 3. Bone scan (A), ${ }^{18} \mathrm{~F}-\mathrm{FES}$ PET (B), and ${ }^{18} \mathrm{~F}-\mathrm{FES} \mathrm{PET} / \mathrm{CT}$ $(C$ and $D)$ images of patient with progressive disease after multiple lines of antihormonal therapy and chemotherapy. Extensive tracer uptake was seen in bone, in lymph nodes, and intracerebrally. Interestingly, ${ }^{18}$ F-FES uptake seemed to be predominant in bone marrow of this patient, in whom laboratory signs of bone marrow infiltration were present.

whom a biopsy was problematic. All 10 had ${ }^{18} \mathrm{~F}-\mathrm{FES}-$ positive metastases. Interestingly, our results indicated that an extensive variance in ${ }^{18} \mathrm{~F}$-FES uptake can be present across positive lesions within individuals (coefficient of variance,

$68 \% \pm 4 \%$ ). This heterogeneity matches findings of multiple biopsies from individual patients showing that a variety of ER levels can be present $(30,31)$. Furthermore, $45 \%$ of the patients with a positive ${ }^{18} \mathrm{~F}$-FES PET finding had both ${ }^{18} \mathrm{~F}$-FES-positive and ${ }^{18} \mathrm{~F}$-FES-negative metastases. This percentage was higher than previously reported $(10 \%-$ $24 \%$ ) (32), pointing toward the relevance of ${ }^{18} \mathrm{~F}$-FES PET, because it provides knowledge of whole-body tumor ER expression. So far, the consequence of a heterogeneous ER expression for therapy management has received strikingly little attention in the clinic and deserves further exploration.

The last group of patients in our study underwent ${ }^{18} \mathrm{~F}$ FES PET to differentiate between distant recurrences originating from the earlier ER-positive primary breast tumor and metastases originating from a second tumor. The ERspecific ${ }^{18} \mathrm{~F}$-FES tracer permitted noninvasive differentiation between tumor types, avoiding the necessity of additional (invasive) diagnostic procedures and leading to early institution of the right drug.

Our study and approach has limitations. We provide an analysis of the value of ${ }^{18} \mathrm{~F}-\mathrm{FES}$ PET in the standard clinical situation. The standardized questionnaires we used can still be subject to bias and should be interpreted with caution. Therapy changes were carefully made while taking into account earlier therapies, other imaging results, and clinical presentation. Imaging analysis was performed retrospectively, possibly leading to potential bias. To minimize bias favoring ${ }^{18} \mathrm{~F}$-FES PET, we performed a central revision of all conventional imaging. Because of the absence of a clear golden standard, sensitivities and specificities cannot be given. Prospective studies should be performed to prove that ${ }^{18} \mathrm{~F}$-FES PET can replace the biopsy for treatment decisions.

Current ${ }^{18} \mathrm{~F}$-FES PET studies do not describe its capacity to detect liver metastases. The physiologic uptake in the liver due to metabolization well exceeds the ${ }^{18} \mathrm{~F}$-FES up-

FIGURE 4. This patient presented with neurologic symptoms of root C6 5 y after primary breast cancer diagnosis. On MRI (A), pathologic processes were suspected in $\mathrm{C} 6$ and T4. Biopsy to prove that these were metastases and originated from prior primary breast cancer was considered too risky. ${ }^{18} \mathrm{~F}-\mathrm{FES}$ uptake was observed in suspected metastases in C6 and T4 (B). ${ }^{18} \mathrm{~F}-\mathrm{FES}$ PET/CT images (C) matched MRI findings. No other pathologic uptake was observed.

A

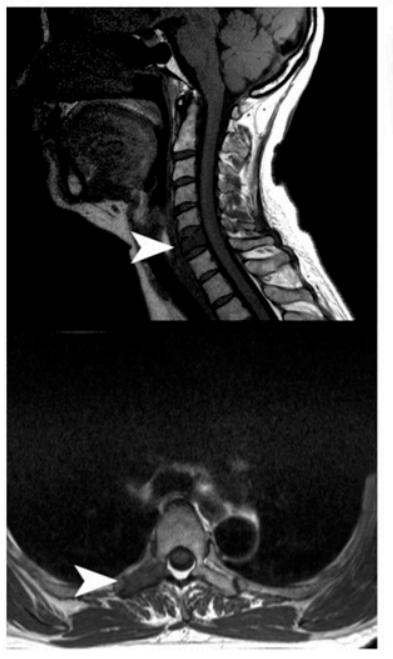

B

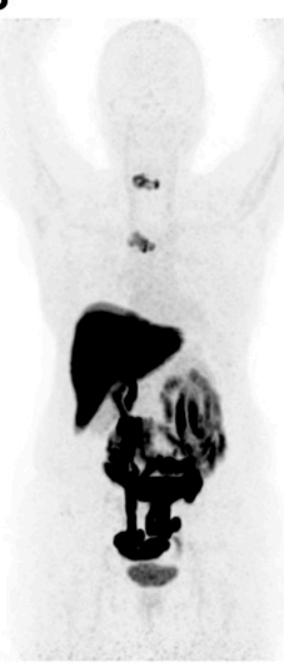

C

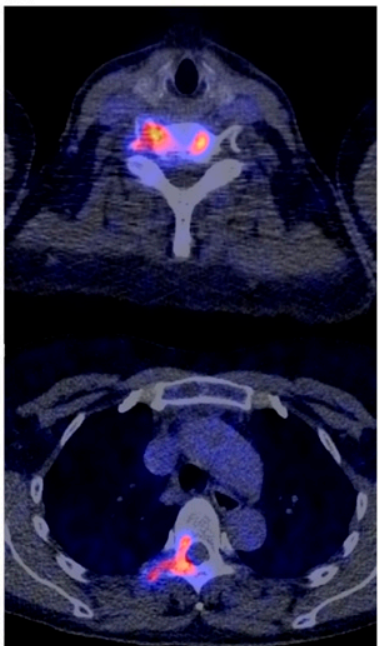


TABLE 4

Changes in Therapeutic Strategy after ${ }^{18} \mathrm{~F}-\mathrm{FES}$ PET

\begin{tabular}{llll}
\hline \multicolumn{1}{c}{ Intended therapy } & \multicolumn{1}{c}{${ }^{18}$ F-FES PET finding } & Final therapy & Patients $(n)$ \\
\hline Chemotherapy & Strong ER positivity & Antihormonal therapy & 4 \\
Wait-and-see policy & 18 F-FES-positive relapse & Antihormonal therapy & 3 \\
Antihormonal therapy & New bone metastases & + Radiotherapy & 4 \\
& New bone metastases & +Bisphosphonates & 1 \\
& ${ }^{18}$ F-FES-negative metastases & Chemotherapy & 2 \\
Radiotherapy & Negative ${ }^{18}$ F-FES PET & Wait-and-see policy & 2
\end{tabular}

Changes in therapeutic strategy after ${ }^{18}$ F-FES PET findings are combined with patient history, prior therapies, clinical presentation, and all findings on conventional imaging techniques.

take that is seen in the uterus (33) or most ER-positive metastases. In our study, the detection of liver metastases by ${ }^{18} \mathrm{~F}$-FES PET was poor, and 1 histologic ER-positive metastasis was not detected. We did observe focal cold lesions in 2 other patients. Quantification of ${ }^{18} \mathrm{~F}$-FES uptake in these lesions was hampered by the high physiologic uptake in surrounding tissue. Because liver biopsies were not available in these patients, it is unknown whether the cold appearance can be explained by focal loss of ER expression. ${ }^{18}$ F-FES-negative liver metastases should therefore be evaluated by immunohistochemistry in future studies.

There are several factors other than ER expression that might affect ${ }^{18} \mathrm{~F}$-FES uptake. Because of the resolution limitations of PET, small metastases may not show ${ }^{18} \mathrm{~F}$ FES uptake. In addition, the presence of estrogen analogs such as tamoxifen can block tumor ${ }^{18}$ F-FES uptake (22). For this reason, we chose an arbitrary drug withdrawal period of $5 \mathrm{wk}$ for ER ligands. Patients who discontinued fulvestrant 5 wk before ${ }^{18} \mathrm{~F}$-FES PET had a high rate of ${ }^{18}$ F-FES-negative lesions (14/20 metastases). A 5-wk drug withdrawal period may therefore not have been sufficient to exclude occupancy of ERs by this drug with a long half-life of $40 \mathrm{~d}$. The only premenopausal patient in this study had ${ }^{18}$ F-FES uptake values well below the $95 \%$ confidence interval of postmenopausal patients. In a previous study in primary breast cancer patients, only 6 of 10 patients with ER-positive tumors showed focal ${ }^{18} \mathrm{~F}$-FES uptake (16). Although not mentioned in the discussion of this report, all 4 patients with a false-negative ${ }^{18} \mathrm{~F}$-FES PET finding were most likely premenopausal because their ages ranged from 34 to $45 \mathrm{y}$, whereas the age of the 6 patients with a truepositive ${ }^{18} \mathrm{~F}$-FES PET finding ranged from 56 to $71 \mathrm{y}$. Together, these data underline the possibility that background estrogen levels influence ${ }^{18} \mathrm{~F}$-FES uptake, which warrants further exploration.

\section{CONCLUSION}

Whole-body imaging of ER expression with ${ }^{18}$ F-FES PET can aid in diagnosis and support treatment decision making in ER-positive breast cancer patients presenting with a variety of diagnostic dilemmas. On the basis of our results, we do not recommend using ${ }^{18} \mathrm{~F}$-FES PET to evaluate liver metastases. The therapeutic consequences of having heterogeneous ${ }^{18} \mathrm{~F}$-FES uptake and the influence of background estrogen levels should further be explored.

\section{DISCLOSURE STATEMENT}

The costs of publication of this article were defrayed in part by the payment of page charges. Therefore, and solely to indicate this fact, this article is hereby marked "advertisement" in accordance with 18 USC section 1734.

\section{ACKNOWLEDGMENTS}

We thank Dr. Riemer H.J.A. Slart for carefully evaluating all bone scans and Johannes $\mathrm{H}$. van Snick for providing ${ }^{18} \mathrm{~F}-$ FES PET and PET/CT images for external revision. Portions of this study were supported by grant KWF-project RUG 2009-4529 of the Dutch Cancer Society. This paper was presented in part at the Annual Conference of the American Society of Clinical Oncology, June 2010, and at the Annual Congress of the European Association of Nuclear Medicine, Vienna, October 2010. No other potential conflict of interest relevant to this article was reported.

\section{REFERENCES}

1. Altekruse SF, Kosary CL, Krapcho M, et al. SEER Cancer Statistics Review, 1975-2007. Bethesda, MD: National Cancer Institute; based on November 2009 SEER data submission. 2010. Available from: http://seer.cancer.gov. Accessed December 9, 2011.

2. Blamey RW, Hornmark-Stenstam B, Ball G, et al. ONCOPOOL: a European database for 16,944 cases of breast cancer. Eur J Cancer. 2010;46:56-71.

3. Allred DC, Harvey JM, Berardo M, Clark GM. Prognostic and predictive factors in breast cancer by immunohistochemical analysis. Mod Pathol. 1998;11:155-168.

4. Harvey JM, Clark GM, Osborne CK, Allred DC. Estrogen receptor status by immunohistochemistry is superior to the ligand-binding assay for predicting response to adjuvant endocrine therapy in breast cancer. J Clin Oncol. 1999; 17:1474-1481.

5. DeSombre ER, Thorpe SM, Rose C, et al. Prognostic usefulness of estrogen receptor immunocytochemical assays for human breast cancer. Cancer Res. 1986;46:4256s-4264s.

6. Pusztai L, Mazouni C, Anderson K, Wu Y, Symmans WF. Molecular classification of breast cancer: Limitations and potential. Oncologist. 2006;11:868-877.

7. Sharangpani GM, Joshi AS, Porter K, et al. Semi-automated imaging system to quantitate estrogen and progesterone receptor immunoreactivity in human breast cancer. J Microsc. 2007;226:244-255. 
8. Hammond ME, Hayes DF, Dowsett M, et al. American Society of Clinical Oncology/College of American Pathologists guideline recommendations for immunohistochemical testing of estrogen and progesterone receptors in breast cancer. J Clin Oncol. 2010;28:2784-2795.

9. Early Breast Cancer Trialists' Collaborative Group (EBCTCG), Davies C, Godwin J, et al. Relevance of breast cancer hormone receptors and other factors to the efficacy of adjuvant tamoxifen: patient-level meta-analysis of randomised trials. Lancet. 2011;378:771-784.

10. Amir E, Clemons M, Freedman OC, et al. Tissue confirmation of disease recurrence in patients with breast cancer: pooled analysis of two large prospective studies [abstract]. J Clin Oncol. 2010;28(suppl):1007.

11. Simmons C, Miller N, Geddie W, et al. Does confirmatory tumor biopsy alter the management of breast cancer patients with distant metastases? Ann Oncol. 2009;20:1499-1504.

12. Karlsson E, Lindstrom LS, Wilking U, Skoog L, Johansson U, Bergh J. Discordance in hormone receptor status in breast cancer during tumor progression [abstract]. J Clin Oncol. 2010;28(suppl):1009.

13. NCCN Clinical Practice Guidelines in Clinical Oncology, version 2.2011. 2011. Available from: http://www.nccn.org/professionals/physician_gls/PDF/breast. pdf. Accessed December 9, 2011.

14. Cardoso F, Senkus-Konefka E, Fallowfield L, Costa A, Castiglione M, ESMO Guidelines Working Group. Locally recurrent or metastatic breast cancer: ESMO clinical practice guidelines for diagnosis, treatment and follow-up. Ann Oncol. 2010;21 (suppl)5:v15-19.

15. Chung GG, Zerkowski MP, Ghosh S, Camp RL, Rimm DL. Quantitative analysis of estrogen receptor heterogeneity in breast cancer. Lab Invest. 2007;87:662669.

16. Dehdashti F, Mortimer JE, Siegel BA, et al. Positron tomographic assessment of estrogen receptors in breast cancer: comparison with FDG-PET and in vitro receptor assays. J Nucl Med. 1995;36:1766-1774.

17. Hospers GA, Helmond FA, de Vries EG, Dierckx RA, de Vries EF. PET imaging of steroid receptor expression in breast and prostate cancer. Curr Pharm Des. 2008;14:3020-3032.

18. McGuire AH, Dehdashti F, Siegel BA, et al. Positron tomographic assessment of 16 alpha- $\left[{ }^{18} \mathrm{~F}\right]$ fluoro-17 beta-estradiol uptake in metastatic breast carcinoma. J Nucl Med. 1991;32:1526-1531.

19. Mintun MA, Welch MJ, Siegel BA, et al. Breast cancer: PET imaging of estrogen receptors. Radiology. 1988;169:45-48.

20. Peterson LM, Mankoff DA, Lawton T, et al. Quantitative imaging of estrogen receptor expression in breast cancer with PET and ${ }^{18} \mathrm{~F}$-fluoroestradiol. $\mathrm{J}$ Nucl Med. 2008;49:367-374.
21. Mortimer JE, Dehdashti F, Siegel BA, Trinkaus K, Katzenellenbogen JA, Welch MJ. Metabolic flare: indicator of hormone responsiveness in advanced breast cancer. J Clin Oncol. 2001;19:2797-2803.

22. Dehdashti F, Flanagan FL, Mortimer JE, Katzenellenbogen JA, Welch MJ, Siegel BA. Positron emission tomographic assessment of "metabolic flare" to predict response of metastatic breast cancer to antiestrogen therapy. Eur J Nucl Med. 1999;26:51-56.

23. Linden HM, Stekhova SA, Link JM, et al. Quantitative fluoroestradiol positron emission tomography imaging predicts response to endocrine treatment in breast cancer. J Clin Oncol. 2006;24:2793-2799.

24. Roemer J, Steinbach J, Kasch H. Studies on the synthesis of $16 \alpha-\left[{ }^{18}\right.$ F $]$ fluoroestradiol. Appl Radiat Isot. 1996;47:395-399.

25. Boellaard R, O'Doherty MJ, Weber WA, et al. FDG PET and PET/CT: EANM procedure guidelines for tumour PET imaging-version 1.0. Eur J Nucl Med Mol Imaging. 2010;37:181-200.

26. Herder GJ, Van Tinteren H, Comans EF, et al. Prospective use of serial questionnaires to evaluate the therapeutic efficacy of ${ }^{18} \mathrm{~F}$-fluorodeoxyglucose (FDG) positron emission tomography (PET) in suspected lung cancer. Thorax. 2003;58: 47-51.

27. Eisenhauer EA, Therasse P, Bogaerts J, et al. New response evaluation criteria in solid tumours: revised RECIST guideline (version 1.1). Eur J Cancer. 2009; 45:228-247.

28. Oude Munnink TH, Nagengast WB, Brouwers AH, et al. Molecular imaging of breast cancer. Breast. 2009;18(suppl) 3:S66-S73.

29. Barentsz J, Takahashi S, Oyen W, et al. Commonly used imaging techniques for diagnosis and staging. J Clin Oncol. 2006;24:3234-3244.

30. Layfield LJ, Saria E, Mooney EE, Liu K, Dodge RR. Tissue heterogeneity of immunohistochemically detected estrogen receptor: implications for image analysis quantification. Am J Clin Pathol. 1998;110:758-764.

31. van Netten JP, Algard FT, Coy P, et al. Heterogeneous estrogen receptor levels detected via multiple microsamples from individual breast cancers. Cancer. 1985;56:2019-2024.

32. Mortimer JE, Dehdashti F, Siegel BA, Katzenellenbogen JA, Fracasso P, Welch MJ. Positron emission tomography with 2-[ $\left.{ }^{18} \mathrm{~F}\right]$ fluoro-2-deoxy-D-glucose and 16alpha- $\left[{ }^{18} \mathrm{~F}\right]$ fluoro-17beta-estradiol in breast cancer: correlation with estrogen receptor status and response to systemic therapy. Clin Cancer Res. 1996;2:933-939.

33. Mankoff DA, Peterson LM, Tewson TJ, et al. $\left[{ }^{18} \mathrm{~F}\right]$ fluoroestradiol radiation dosimetry in human PET studies. J Nucl Med. 2001;42:679-684. 